\title{
Current and Future Oncology Management in the United States
}

\author{
Anne Runyan, BA; Jordan Banks, MPA; and Daniele Severi Bruni, MS
}

\begin{abstract}
BACKGROUND: The cost of treating cancer patients is high and rising in the United States. Payers are exposed to cost through doctor visits, laboratory tests, imaging tests, radiation treatment, drugs, hospital stays, surgery, home care, transportation and travel, and caregiving. This study focuses on the cost of medication from the viewpoint of U.S. payers. Although new tools for managing these costs have been gaining attention, prices continue to rise, and challenges to managing costs remain high. Innovative tools are necessary for controlling the cost of care in oncology, but their effectiveness is still unclear.
\end{abstract}

OBJECTIVES: To (a) gauge payer perceptions of current and future cost management of innovative oncology drugs and (b) predict which management tools will increase in prevalence by 2020-2022.

METHODS: A literature search of cost and management of oncology created the foundation for developing a survey for U.S. payers. The mobile survey was completed on devices such as smart phones or tablets. Payers were asked about general oncology product management, use of specific management tools today, management challenges, and expected use of specific management tools in 2020-2022. Management tools were segmented into traditional (used across many therapeutic categories), oncology-specific (used in oncology but not routinely used in other disease areas), and systemic (not product-specific but that affect the way services are provided and funded). Specific questions for managing the cost of care in non-small cell lung cancer (NSCLC) and chronic lymphocytic leukemia (CLL) were included in the survey. NSCLC and CLL were chosen because of their diverse clinical characteristics and the level of innovation in these disease areas. The survey was fielded from May 31, 2017, to June 15, 2017. Results consisted of simple descriptive statistical analysis weighted by the payer's reported organizational covered lives.

RESULTS: Payers were concerned with the high cost and budget impact of oncology drugs and considered these a high priority for management. However, they continue to use traditional management tools such as manage to FDA label, quantity limits, step edits, and reauthorizations, which are ineffective in controlling cost. More innovative management tools such as pathways of care are available but are not yet widely adopted. Payers hope to better control oncology cost in the future; however, specific questions pertaining to the management of NSCLC and CLL indicate that minimal changes in cost management will occur by 2020-2022.

CONCLUSIONS: Despite an increasing number of innovative cost management tools, challenges remain for managing oncology medication costs. New incentives are being generated, but barriers to their implementation will continue to restrict use through 2020-2022.

J Manag Care Spec Pharm. 2019;25(2):272-81

Copyright @ 2019, Academy of Managed Care Pharmacy. All rights reserved.

\section{What is already known about this subject}

Oncology treatments place a high-cost burden on the U.S. health care system.

A lack of formal health technology assessments contribute to reduced effectiveness in U.S. management, relative to other markets. New tools are being used to contain cost, including value frameworks, site of care optimization, and oncology care models.

\section{What this study adds}

This study adds a greater understanding of the prevalence and effectiveness of traditional tools, oncology-specific tools, and systemic management tools being used by payers today.

Payer-reported information on the evolution of oncology management for 2020-2022 is provided.

This study gauges the current and future use of traditional and innovative tools by assessing specific case studies of NSCLC and CLL.

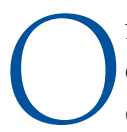
ncology continues to be a major cost driver in, and cost burden on, the U.S. health system. ${ }^{1}$ Direct costs of treating cancer include doctor visits, laboratory tests, imaging tests, radiation treatment, hospital stays, home care, and drug costs. There are also indirect costs to treating cancer that include transportation and travel, family and living expenses during treatment, caregiving, lost wages, and legal and financial issues. ${ }^{2,3}$

Drug costs are a major driver of overall oncology cost and put a significant burden on payers' budgets. The 2017 Magellan assessment of medical pharmacy trends found that oncology and oncology supportive care comprise $45 \%$ of commercial medical benefit drug per member per month spending and $60 \%$ of Medicare medical benefit drug per member per month spending. ${ }^{1}$

Oncology drug costs increase after launch of new drugs, despite increased competition. ${ }^{4}$ An IMS analysis found that the average cost for oncology drugs doubled from $\$ 5,000$ to $\$ 10,000$ per month between 2003 and 2013. ${ }^{5}$ Another study found that "spending on Part B drugs - a category dominated by drugs used to treat cancer-rose from $\$ 3$ billion in 1997 to $\$ 11$ billion in 2004 (an increase of 267\%), compared with a rise in overall Medicare spending from $\$ 210$ billion to $\$ 309$ billion (an increase of 47\%) during the same time period." 
Despite high and rising costs of oncology drugs, payers struggle to contain and control their costs in this segment of patients. One challenge is that payers cannot use patient cost sharing to influence demand in oncology as effectively as in other therapeutic areas. When oncology drugs are administered in a physician's office, patients have a fixed percentage of cost sharing under the medical benefit. This fixed percentage is usually $20 \%$, up to a capped out-of-pocket maximum. ${ }^{7}$ There is no specific drug out-of-pocket cost share, which makes it difficult for payers to impose patient cost incentives to influence preference toward certain drugs, something that they are able to do for oral drugs managed under the pharmacy benefit. However, within oncology even oral drugs under the pharmacy benefit are not strictly managed. ${ }^{8}$ Because of the high cost of oncology drugs, patients often reach their annual out-ofpocket cost maximum within the first month of treatment. ${ }^{9}$ Furthermore, because of strong patient advocacy in oncology, there are often patient assistance programs available to help patients manage drug costs. As many as $87 \%$ of approved products have a patient assistance program available..$^{10}$

Another challenge to oncology drug management is the segmented patient population. There are many subpopulations within oncology indications, and treatments can be based on genetic markers. ${ }^{11}$ For example, treatment of non-small cell lung cancer (NSCLC) may depend on whether the cancer tests positive for $\mathrm{PD}-\mathrm{Ll}$ protein and whether the tumor has an abnormal epidermal growth factor receptor (EGFR) or anaplastic lymphoma kinase (ALK) gene. ${ }^{12}$ This segmentation limits the direct competition across products and the ability of payers to select preferred brands.

Furthermore, traditional tools used to control prices and use are restricted in the oncology sector in Medicare because laws and regulations protect cancer drug use and costs from being limited. ${ }^{6}$ For example, for oncology drugs administered in a physician's office under Medicare Part B, Medicare is required "to cover any drug used in an 'anticancer chemotherapeutic regimen' as long as the use is 'for a medically accepted indication." A medically accepted indication is defined as "uses approved by the Food and Drug Administration, uses listed in one of several drug compendia, and uses supported in the peer-reviewed medical literature." In the commercial segment, payers are not bound by law to provide coverage but are still hesitant to deny care.

Although historically it has been difficult for payers to control oncology costs, new strategies are emerging that may help with cost containment. For example, 1 study found that 4 of the largest payers in the United States (Aetna, Anthem, United Healthcare, and Medicare) are beginning to shift risk to physicians through positive financial incentives. ${ }^{13}$ In addition, a 2016 Decision Resources Group article found that CVS and Express Scripts, 2 large pharmacy benefit managers (PBMs), have developed programs that review the value of cancer drugs per indication to determine pricing and access. ${ }^{14}$ Express Scripts launched its Oncology Care Value Program in 2016 with a focus on aligning cost with treatment outcomes in prostate cancer, lung cancer, and renal cell carcinoma. ${ }^{14}$

There are also nonpayer specific initiatives. For example, the American Society of Clinical Oncology (ASCO) developed a new payment reform model to improve quality and affordability of cancer care. It is evaluating a proposed payment model called "Patient Centered Oncology Payment: Payment Reform to Support Higher Quality, More Affordable Patient Care." This is "an alternative payment model, which ensures that the full range of services needed by patients with cancer is supported within a value-based reimbursement system that increases patient satisfaction and cost savings." ${ }^{15}$ Also, the Oncology Care Model (OCM) has been implemented by the Center for Medicare \& Medicaid Innovation as a new tool intended to control oncology costs. ${ }^{16}$ The OCM is a payment and delivery model "which aims to provide higher quality, more highly coordinated oncology care at the same or lower cost to Medicare."16 As of July 2016, seventeen health insurance companies and nearly 200 physician practices had been selected to participate in the OCM, which includes more than 3,200 oncologists and has affected about 155,000 Medicare lives. ${ }^{16}$ The OCM provides practices with positive financial incentives that reward meeting certain performance measures.

Given the challenges of controlling oncology drug costs, the objective of this research was to test 3 hypotheses:

- Traditional management tools are primarily used in oncology today with minimal results.

- Management is challenging due to limited competition among products, disease complexity, and a high level of patient segmentation.

- In 2020-2022, payers expect that cost containment of oncology drugs will remain limited, despite the emergence of new management strategies.

\section{Methods}

A search was conducted for literature on current cost management in oncology and expected evolution of management, using PubMed and Google Scholar databases to find published articles from 2010-2017. Several search terms were used individually and in combination to target oncology management and cost publications. The search was not a formal review but was intended to target notable contributions to the literature. Based on gaps found in the current literature, a survey was developed and deployed to U.S. payers in order to better understand current and future trends in the management of oncology drugs.

The survey was programmed in an online survey tool and sent to respondents' smart phones and other mobile devices. Survey responses were collected from May 31, 2017, to June 15, 2017. Only complete surveys were accepted, and payers could only 


\section{TABLE 1 Operational Definitions}

\begin{tabular}{|c|c|}
\hline Term & Definition \\
\hline \multicolumn{2}{|l|}{ Traditional management tools } \\
\hline Quantity limits & Payer defines how much of a drug the patient can get during a specified time period \\
\hline Manage to label & Payer restricts use to FDA-labeled indication \\
\hline Split fills & $\begin{array}{l}\text { Program where pharmacy can provide a partial fill of the member's first prescription before filling the full } \\
\text { specified time period of a prescription }\end{array}$ \\
\hline Reauthorizations & Reauthorization to continue therapy must be sought at regular intervals \\
\hline $\begin{array}{l}\text { Step edits for products recommended in the } \\
\text { same line of therapy by NCCN compendia }\end{array}$ & $\begin{array}{l}\text { Payer requires patient to try a preferred drug before trying the product if the step edit follows NCCN } \\
\text { compendia }\end{array}$ \\
\hline Step edits independent of NCCN guidelines & $\begin{array}{l}\text { Payer requires patient to try a preferred drug before trying the product where this step edit does not } \\
\text { follow NCCN compendia }\end{array}$ \\
\hline $\begin{array}{l}\text { Blocking agents and having them only available } \\
\text { by medical exception }\end{array}$ & $\begin{array}{l}\text { Payer does not allow access to a product except through a medical exception or an appeal process by the } \\
\text { physician; such an approach requires a significant administrative effort from the prescriber }\end{array}$ \\
\hline \begin{tabular}{|l|l} 
Preferred through tiering & \\
\end{tabular} & Payer uses copay differentials to influence preference toward specific drugs \\
\hline \multicolumn{2}{|l|}{ Oncology-specific management tools } \\
\hline Pathways without risk & $\begin{array}{l}\text { Comprehensive, evidence-based treatment protocols that give direction on how to provide cancer care; } \\
\text { pathways without risk incentivize physicians to follow the pathway with an upside risk (e.g., positive } \\
\text { financial incentive) }\end{array}$ \\
\hline Pathways with risk & $\begin{array}{l}\text { Comprehensive, evidence-based treatment protocols that give direction on how to provide cancer care; } \\
\text { pathways with risk incentivize physicians with downside and upside risk (e.g., a fee is implemented if } \\
\text { pathway is not followed, or overall clinician reimbursement rate is dependent on the adoption of the } \\
\text { implementation of the pathway) }\end{array}$ \\
\hline $\begin{array}{l}\text { Buy-and-bill incentives to influence preference } \\
\text { toward branded agents }\end{array}$ & Payer provides a higher reimbursement rate to clinicians for preferred branded products \\
\hline $\begin{array}{l}\text { Buy-and-bill incentives to influence preference } \\
\text { towards generics }\end{array}$ & Payer provides a higher reimbursement rate to clinicians for generic products \\
\hline \multicolumn{2}{|l|}{ Systemic management tools } \\
\hline $\begin{array}{l}\text { Pursuing oncology-specific models, such as } \\
\text { oncology care models }\end{array}$ & $\begin{array}{l}\text { A payment delivery model where participating groups provide enhanced patient services, use data to drive } \\
\text { continuous quality improvement, and use certified electronic health record technology. Participants in } \\
\text { the CMS OCM program receive a monthly enhanced oncology services payment of } \$ 160 \text { per beneficiary, } \\
\text { performance-based payment for OCM episodes, and regular fee-for-service payments }\end{array}$ \\
\hline $\begin{array}{l}\text { Shifting financial risk through payment system } \\
\text { (e.g., bundled payments) }\end{array}$ & A cost-saving measure where reimbursement is based on expected costs of episodes of care \\
\hline $\begin{array}{l}\text { Restructuring provider networks based on their } \\
\text { ability to manage oncology cost }\end{array}$ & $\begin{array}{l}\text { Payers reduce the network of providers and only contract with oncology centers showing the most rational } \\
\text { and cost-minimizing use of resources }\end{array}$ \\
\hline
\end{tabular}

advance to the next question by providing a response to the previous question. Payers were able to provide comments on responses, which were analyzed, and follow-up was done when appropriate.

Payers were asked about general oncology product management, use of specific management tools, management challenges, and expected use of specific management tools by 2020-2022. Management tools were segmented into traditional (used across therapeutic categories), oncology-specific (used in oncology but not routinely used in other disease areas), and systemic (not product-specific but affecting the way services are provided and funded). A summary of the tools tested and their operational definitions can be found in Table 1 .

Questions on managing the cost of care in NSCLC and chronic lymphocytic leukemia (CLL) were included in the survey to more specifically understand management decisions in oncology. NSCLC and CLL were chosen because of their diverse clinical characteristics, with NSCLC representing management of a large solid tumor class with a relatively high prevalence and CLL representing a hematological malignancy with lower prevalence. For both diseases, there have been significant innovations in the past decade, with additional products in the pipeline creating an increasingly competitive environment. The Appendix contains the full survey (available from the authors at https://mkogp.com/appendixA/).

Respondents were recruited through a panel of payers provided by MKO Global Partners, a life science consulting firm. This panel included medical and pharmacy directors who were members of the pharmacy and therapeutics committees of their organizations and were responsible for formulary decision making. The panel had been built through recruitment of payers over the previous 3 years. A total of 57 payers were targeted of which 21 responded. Each individual payer represented between 600,000 and 15,000,000 covered lives. 


\begin{tabular}{|c|c|c|c|c|}
\hline \multirow[b]{2}{*}{ Challenges } & \multicolumn{2}{|c|}{ Payers Selecting Challenge } & \multicolumn{2}{|c|}{$\begin{array}{l}\text { Lives Represented by } \\
\text { Payers Selecting Challenge }\end{array}$} \\
\hline & $\mathbf{n}$ & $\%$ & n (millions) & $\%$ \\
\hline It is difficult to compare products and select a preferred one & 19.0 & 90 & 115.7 & 95 \\
\hline The patient population is too complex; physicians need to maintain the ability to choose & 13.0 & 62 & 102.9 & 85 \\
\hline The evidence is not mature enough & 12.0 & 57 & 72.9 & 60 \\
\hline Government regulations prevent me from managing this category & 14.0 & 67 & 69.2 & 57 \\
\hline I will receive physician pushback if I manage this category & 11.0 & 52 & 49.1 & 40 \\
\hline There are limited therapeutic agents in this category & 9.0 & 43 & 38.5 & 32 \\
\hline Patient advocacy groups & 7.0 & 33 & 32.8 & 27 \\
\hline Other organizations do not manage this category & 5.0 & 24 & 29.0 & 24 \\
\hline Science advances too quickly & 5.0 & 24 & 27.2 & 22 \\
\hline
\end{tabular}

The survey data was analyzed in July 2017 using Stata 13 SE (StataCorp, College Station, TX) and Microsoft Excel (Microsoft Corporation, Redmond, WA). All reported averages are weighted averages by covered lives. Results were expressed as descriptive statistics (e.g., mean, range, and sum), weighted for the number of covered lives in each organization.

\section{Results}

A total of 21 payers representing 121.5 million covered lives across 18 organizations responded to the survey. The sample represented 75\% commercial lives, 16\% Medicare lives, 8.5\% Medicaid lives, and $0.5 \%$ other lives (e.g., health care exchange). Overall, across the United States, there are approximately 294 million insured lives, so the sample represented about 40\% of insured lives. ${ }^{17,18}$ Medicaid lives were somewhat underrepresented in the sample, with an estimated 19\%. ${ }^{18}$

Our sample included 14 pharmacy directors representing 83.8 million lives and 7 medical directors representing 37.7 million lives. Included were 5 regional managed care organizations (MCOs), 6 national MCOs, 6 PBMs, and 1 integrated delivery network (IDN).

On a scale from 1 to 7 , where 1 was low and 7 was high, payers reported that they were highly concerned about the cost of oncology, rating the budget impact as 6.4. They also considered it a high management priority, rating management priority as 5.1. When compared with other high-cost disease areas such as diabetes, multiple sclerosis, bleeding disorders, rheumatoid arthritis, psoriasis, and hepatitis $C$ virus, oncology was rated as the highest budget impact category. Management priority in oncology was rated in line with management priority in other high-cost disease areas, such as diabetes, hepatitis C, rheumatoid arthritis, multiple sclerosis, psoriasis, and bleeding disorders, and all were considered high management priorities. No differences were reported between medical directors and pharmacy directors, but the sample was not powered to show statistically significant differences across medical and pharmacy directors. IDNs and regional MCOs rated the management priority in oncology lower than national MCOs and PBMs, but the sample was not powered to show statistically significant differences across organization types.

The top 5 challenges to payers for oncology management were difficulty comparing products, complex patient population, lack of mature evidence, government regulations, and physician pushback (Table 2). Medical directors appeared to be more concerned about lack of mature evidence, complex patient populations, and government regulations than pharmacy directors. IDNs were less concerned about inability to compare and select preferred products compared with other payer types. National payers were more concerned about complex patient populations compared with other payer types, and PBMs were less concerned about complex patient populations. Regional payers were more concerned about government regulations than other payer types, and national payers were less concerned with government regulations than other payer types.

Our study showed that payers most commonly manage oncology products to label and by using quantity limits, a soft management tool. Nineteen payers (109.2 million lives) managed oncology products to label, and 19 payers (118.3 million lives) used quantity limits. Split fills and reauthorizations were somewhat common, with split fills used by 12 payers (75.8 million lives) and reauthorizations used by 14 payers (74.0 million lives). Pharmacy directors reported using split fills more often than medical directors. Pharmacy directors also reported using reauthorizations more often than medical directors. Tiering differentials, step edits, and blocking agents from formulary were not commonly used. Tiering differentials were reported in use by 4 payers (27.5 million lives); step edits independent of National Comprehensive Cancer Network (NCCN) guidelines were used by 4 payers (19.0 million lives); and 3 payers (29.1 million lives) reported the use of blocking agents. Pharmacy directors reported using split fills and reauthorizations more often than medical directors. In the future (the next 3-5 years), 


\section{TABLE 3 Payer Oncology Drug Management Tools}

\begin{tabular}{|c|c|c|c|c|c|c|c|c|}
\hline & \multicolumn{2}{|c|}{$\begin{array}{l}\text { Number of Payers } \\
\text { Using Tools in } 2017\end{array}$} & \multicolumn{2}{|c|}{$\begin{array}{l}\text { Number of Lives } \\
\text { in } 2017\end{array}$} & \multicolumn{2}{|c|}{$\begin{array}{c}\text { Number of Payers } \\
\text { Expected to Use Tools } \\
\text { in } 2020-2022\end{array}$} & \multicolumn{2}{|c|}{$\begin{array}{l}\text { Number of Lives } \\
\text { Expected in 2020-2022 }\end{array}$} \\
\hline & $\mathrm{n}$ & $\%$ & n (millions) & $\%$ & $\mathbf{n}$ & $\%$ & $\mathrm{n}$ (millions) & $\%$ \\
\hline \multicolumn{9}{|l|}{ Traditional tools } \\
\hline Quantity limits & 19.0 & 90 & 118.3 & 97 & 18.0 & 86 & 106.6 & 88 \\
\hline Manage to label & 19.0 & 90 & 109.2 & 90 & 19.0 & 90 & 107.1 & 88 \\
\hline Split fillsa & 12.0 & 57 & 75.8 & 62 & 16.0 & 76 & 81.5 & 67 \\
\hline Reauthorizations $^{\mathrm{a}}$ & 14.0 & 67 & 74.0 & 61 & 13.0 & 62 & 73.9 & 61 \\
\hline $\begin{array}{l}\text { Step edits for products recommended in the } \\
\text { same line of therapy by NCCN compendia }\end{array}$ & 16.0 & 76 & 43.4 & 36 & 14.0 & 67 & 84.8 & 70 \\
\hline $\begin{array}{l}\text { Blocking agents and having them only } \\
\text { available by medical exception }\end{array}$ & 3.0 & 14 & 29.1 & 24 & 9.0 & 43 & 68.4 & 56 \\
\hline Preferred through tiering & 4.0 & 19 & 27.5 & 23 & 11.0 & 52 & 60.0 & 49 \\
\hline Step edits independent of NCCN guidelines ${ }^{a}$ & 4.0 & 19 & 19.0 & 16 & 8.0 & 38 & 59.2 & 49 \\
\hline \multicolumn{9}{|l|}{ Oncology-specific management tools } \\
\hline Pathways without risk & 6.0 & 29 & 35.7 & 29 & 5.0 & 24 & 28.7 & 24 \\
\hline $\begin{array}{l}\text { Buy-and-bill incentives to influence preference } \\
\text { toward branded agents }\end{array}$ & 3.0 & 14 & 26.7 & 22 & 15.0 & 71 & 67.0 & 55 \\
\hline $\begin{array}{l}\text { Buy-and-bill incentives to influence preference } \\
\text { towards generics }\end{array}$ & 1.0 & 5 & 9.0 & 7 & 6.0 & 29 & 36.7 & 30 \\
\hline Pathways with risk & 1.0 & 5 & 9.0 & 7 & 6.0 & 29 & 30.2 & 25 \\
\hline None of these tools & 13.0 & 62 & 71.6 & 59 & 4.0 & 19 & 41.2 & 34 \\
\hline \multicolumn{9}{|l|}{ Systemic management tools } \\
\hline $\begin{array}{l}\text { Pursuing oncology-specific models, such as } \\
\text { oncology care models }\end{array}$ & 4.0 & 19 & 24.5 & 20 & 11.0 & 52 & 66.2 & 54 \\
\hline $\begin{array}{l}\text { Shifting financial risk through payment } \\
\text { system (e.g., bundled payments) }\end{array}$ & 3.0 & 14 & 24.1 & 20 & 6.0 & 29 & 36.2 & 30 \\
\hline $\begin{array}{l}\text { Restructuring provider networks based on } \\
\text { their ability to reduce oncology cost }\end{array}$ & 1.0 & 5 & 9.0 & 7 & 7.0 & 33 & 43.0 & 52 \\
\hline None of these tools & 15.0 & 71 & 89.7 & 74 & 6.0 & 29 & 31.7 & 26 \\
\hline \multicolumn{9}{|c|}{$\begin{array}{l}\text { Note: This table reflects responses from } 21 \text { payers, representing } 121.5 \text { million lives. } \\
\text { aThere were } 14 \text { pharmacy directors and } 7 \text { medical directors in our sample. Although the sample was not powered to detect statistically significant differences between } \\
\text { medical directors and pharmacy directors, the following differences of }>20 \% \text { between medical directors and pharmacy directors were noted: } \\
\text { - Pharmacy directors reported using split fills and reauthorizations more often than medical directors, with } 79 \% \text { of pharmacy directors and } 14 \% \text { of medical directors } \\
\text { using split fills. } \\
\text { - Pharmacy directors reported using reauthorizations more often than medical directors, with } 71 \% \text { of pharmacy directors and } 43 \% \text { of medical directors using } \\
\text { reauthorizations. } \\
\text { - Pharmacy directors were more likely to implement step edits independent of NCCN guidelines in the future compared with medical directors, with } 50 \% \text { of pharmacy } \\
\text { directors and } 14 \% \text { of medical directors expected to use step edits independent of NCCN guidelines in 3-5 years. } \\
\text { - Medical directors were more likely to pursue oncology-specific models such as CMS's Oncology Care Model, with } 43 \% \text { of medical directors and } 7 \% \text { of pharmacy } \\
\text { directors pursuing oncology-specific models. } \\
\text { CMS = Center for Medicare E Medicaid Innovation; NCCN = National Comprehensive Cancer Network. }\end{array}$} \\
\hline
\end{tabular}

use of step edits and blocking agents from formulary was expected to become more common, with 8 payers (59.2 million lives) expecting to implement step edits independent of NCCN guidelines, and 9 payers (68.4 million lives) expecting to block certain agents from formulary (Table 3). Pharmacy directors were more likely to implement step edits independent of NCCN guidelines compared with medical directors.

Regarding oncology-specific utilization management tools, few were being used at the time of the survey. Pathways of care without risk were the most common, with 6 payers (35.7 million lives) using this tool. In the future, payers expected to increase use of buy-and-bill incentives to influence preference toward generics and preferred branded agents covered under the medical benefit. For example, payers indicated that they would change reimbursement markup on the average selling price (ASP) to provide less incentive to use more expensive branded products. In 2017, buyand-bill incentives to influence preference toward preferred brands were used by 3 payers (26.7 million lives), and buyand-bill incentives to influence preference toward generics were used by 1 payer $(9.0$ million lives). In the future, 15 payers (67.0 million lives) expected to use buy-and-bill 


\begin{tabular}{|c|c|c|}
\hline \multicolumn{3}{|c|}{$\begin{array}{l}\text { Payer-Reported Budget Impact of } \\
\text { NSCLC and CLL Agents }\end{array}$} \\
\hline & 2017 & 2020-2022 \\
\hline \multicolumn{3}{|l|}{ NSCLC } \\
\hline Pembrolizumab (Keytruda) & 5.5 & 5.9 \\
\hline Nivolumab (Opdivo)/ipilimumab (Yervoy) & 4.2 & 4.7 \\
\hline Ramucirumab (Cyramza) & 4.3 & 4.6 \\
\hline Atezolizumab (Tecentriq) & 5.4 & 5.5 \\
\hline \multicolumn{3}{|l|}{ CLL } \\
\hline Venetoclax (Venclexta) & 3.8 & 4.0 \\
\hline Ofatumumab (Arzerra) & 4.0 & 4.2 \\
\hline Idelalisib (Zydelig) & 4.3 & 4.6 \\
\hline Obinutuzumab (Gazyva) & 4.4 & 4.6 \\
\hline Ibrutinib (Imbruvica) & 4.8 & 5.2 \\
\hline Rituximab (Rituxan) & 5.0 & 4.0 \\
\hline \multicolumn{3}{|c|}{$\begin{array}{l}\text { Note: Payers were rated on a scale of 1-5, weighted by organization covered lives, } \\
\text { where } 1 \text { was low and } 5 \text { was high. } \\
C L L=\text { chronic lymphocytic leukemia; NSCLC =non-small cell lung cancer. }\end{array}$} \\
\hline
\end{tabular}

incentives to influence preference toward specific branded agents, and 6 payers (36.7 million lives) expected to use buy-and-bill incentives to influence preference toward generics. In addition, payers expected that use of pathways of care with risk will become more common. While only 1 payer $(9.0$ million lives) used pathways of care with risk in 2017, in 3-5 years 6 payers (30.2 million lives) plan to use pathways of care (Table 3).

Like oncology-specific management tools, systemic tools were not often used by U.S. payers in oncology at the time of the survey. The most commonly used strategy was pursuing oncology-specific models such as oncology care models, with 4 payers (24.5 million lives) using this tool. Shifting financial risk to providers was the next most common tool, with 3 payers (24.1 million lives) using this tool. Only 1 payer (9.0 million lives) reported that it was currently restructuring provider networks based on the ability to reduce oncology cost. In the future, 11 payers (66.2 million lives) expected to pursue oncology-specific models such as oncology care models; 6 payers (36.1 million lives) expected to shift financial risk to providers through payment systems (e.g., bundled payments); and 7 payers (52.0 million lives) expected that they will restructure provider networks based on their ability to reduce oncology cost (Table 3).

Although payers said they would use more management tools in oncology in the future, when asked in general, when presented with the specific disease areas of NSCLC and CLL, they indicated a lower likelihood of managing treatments. This indication is despite moderately high budget impact for currently available products in NSCLC and CLL (Table 4).

For NSCLC and CLL, very few payers reported that they were currently managing products beyond label in the commercial book of business. The numbers are expected to only increase marginally in 3-5 years, with a handful of payers reporting that they will manage certain treatments beyond label (Table 5). A similar trend was seen for beyond label management in the Medicare book of business for these 2 diseases (Table 5).

When probed on specific management tools, the only management strategy being used in 2017 for NSCLC was use of provider-developed pathways to manage the category. This strategy was only used by 1 payer $(9.0$ million commercial and Medicare lives). In 3-5 years, a few more tools were indicated to be used in the commercial book of business (Table 5).

In 2017, the only commercial plan restrictions used for CLL were use of provider-developed pathways to manage (used by 2 payers representing 13.8 million lives), excluding an agent from formulary (used by 1 payer representing 4.8 million lives), use of management tactics such as split fills (used by 1 payer representing 4.8 million lives), and not providing coverage for off-label use despite compendia (used by 1 payer representing 4.8 million lives). In Medicare, the only tool being used was utilization of provider-developed pathways to manage and was used by 1 payer ( 9.0 million lives; Table 5 ).

In the future, use of more strict management tools will become somewhat more common, but most payers will continue to remain relatively unrestrictive. Increased management is more likely in NSCLC than CLL. Results for Medicare restrictions on CLL and NSCLC agents are similar to those for commercial lives (Table 5).

\section{Discussion}

Our research confirms that payer-reported management is limited in oncology despite the recent launch of high-cost drugs and high budget impact of the category. Most oncology drugs are managed to label with quantity limits being used, along with split fills in some cases. However, payer responses indicated that for some cancer types, especially large solid tumors where there are multiple products commercially available and approved for the same indication (e.g., NSCLC, prostate cancer, and breast cancer), step edits are sometimes used.

Today, a few payers are using pathways of care without risk to providers, but most are not using pathways at all. This result suggests that physicians are not being incentivized by payer reimbursement mechanisms to follow published pathways, limiting the possible effectiveness of this management tool. Payers limit incentives today because they perceive an inability to drive patients to specific branded products until there is evidence of equivalency because this is a complex environment for treatment decisions. Pathways typically follow NCCN published guidelines, leaving room for restriction when recommendations become more specific over time.

Buy-and-bill incentives are also not commonly used by payers to control oncology costs. Payers who do use these incentives either do so by providing higher reimbursement rates for generic products, implementing a fee schedule, or 


\section{TABLE 5 Commercial and Medicare Restrictions on NSCLC and CLL Agents Today and Expected} in 3-5 Years

\begin{tabular}{|c|c|c|c|c|c|c|c|c|}
\hline & \multicolumn{2}{|c|}{\begin{tabular}{|c|} 
Number of Payers \\
Who Restrict Agents \\
Today
\end{tabular}} & \multicolumn{2}{|c|}{$\begin{array}{c}\text { Number of Lives } \\
\text { Today }\end{array}$} & \multicolumn{2}{|c|}{\begin{tabular}{|c|} 
Number of Payers \\
Expected to Restrict \\
Agents in 3-5 Years \\
\end{tabular}} & \multicolumn{2}{|c|}{$\begin{array}{c}\text { Number of Lives in } \\
3-5 \text { Years }\end{array}$} \\
\hline & $\mathbf{n}$ & $\%$ & $\begin{array}{c}\mathrm{n} \\
\text { (millions) }\end{array}$ & $\%$ & $\mathrm{n}$ & $\%$ & $\begin{array}{c}\mathrm{n} \\
\text { (millions) }\end{array}$ & $\%$ \\
\hline \multicolumn{9}{|l|}{ NSCLC: commercial } \\
\hline Use provider-developed pathways to manage & 1.0 & 5 & 9.0 & 7 & 3.0 & 14 & 15.8 & 13 \\
\hline $\begin{array}{l}\text { Buy-and-bill incentives to influence preference toward generic } \\
\text { agents }\end{array}$ & 0.0 & 0 & 0.0 & 0 & 2.0 & 10 & 11.0 & 9 \\
\hline $\begin{array}{l}\text { Buy-and-bill incentives to influence preference toward branded } \\
\text { agents }\end{array}$ & 0.0 & 0 & 0.0 & 0 & 0.0 & 0 & 0.0 & 0 \\
\hline Use of value frameworks (e.g., ASCO or ICER )a & 0.0 & 0 & 0.0 & 0 & 4.0 & 19 & 17.1 & 14 \\
\hline $\begin{array}{l}\text { Enter in risk-sharing agreements with providers using pathways } \\
\text { (narrower than NCCN guidelines) to manage }\end{array}$ & 0.0 & 0 & 0.0 & 0 & 2.0 & 10 & 13.8 & 11 \\
\hline Clinical pathways for providers, without risk sharing & 0.0 & 0 & 0.0 & 0 & 0.0 & 0 & 0.0 & 0 \\
\hline Excluded an agent from formulary/coverage & 0.0 & 0 & 0.0 & 0 & 3.0 & 14 & 8.1 & 7 \\
\hline $\begin{array}{l}\text { Implement step edits that require use of one product over } \\
\text { another in the same line of therapy per guidelines }\end{array}$ & 0.0 & 0 & 0.0 & 0 & 3.0 & 14 & 12.3 & 10 \\
\hline Use management tools such as split fills & 0.0 & 0 & 0.0 & 0 & 2.0 & 10 & 6.8 & 6 \\
\hline $\begin{array}{l}\text { Drive use through tiering differentials for like products (same } \\
\text { line of therapy or MOA) }\end{array}$ & 0.0 & 0 & 0.0 & 0 & 2.0 & 10 & 10.3 & 8 \\
\hline $\begin{array}{l}\text { Not providing coverage for off-label use (not FDA approved) } \\
\text { despite NCCN compendia }\end{array}$ & 0.0 & 0 & 0.0 & 0 & 1.0 & 5 & 4.8 & 4 \\
\hline Manage more restrictively than label & 0.0 & 0 & 0.0 & 0 & 1.0 & 5 & 2.0 & 2 \\
\hline \multicolumn{9}{|l|}{ CLL: commercial } \\
\hline Use provider-developed pathways to manage & 2.0 & 10 & 13.8 & 11 & 2.0 & 10 & 13.8 & 11 \\
\hline $\begin{array}{l}\text { Buy-and-bill incentives to influence preference toward generic } \\
\text { agents }\end{array}$ & 0.0 & 0 & 0.0 & 0 & 0.0 & 0 & 0.0 & 0 \\
\hline $\begin{array}{l}\text { Buy-and-bill incentives to influence preference toward branded } \\
\text { agents }\end{array}$ & 0.0 & 0 & 0.0 & 0 & 0.0 & 0 & 0.0 & 0 \\
\hline Use of value frameworks (e.g., ASCO or ICER) & 0.0 & 0 & 0.0 & 0 & 2.0 & 10 & 13.8 & 11 \\
\hline $\begin{array}{l}\text { Enter into risk-sharing agreements with providers using path- } \\
\text { ways (narrower than NCCN guidelines) to manage }\end{array}$ & 0.0 & 0 & 0.0 & 0 & 1.0 & 5 & 9.0 & 7 \\
\hline Clinical pathways for providers, without risk sharing & 0.0 & 0 & 0.0 & 0 & 0.0 & 0 & 0.0 & 0 \\
\hline Excluded an agent from formulary/coverage & 1.0 & 5 & 4.8 & 4 & 1.0 & 5 & 4.8 & 4 \\
\hline $\begin{array}{l}\text { Implement step edits that require use of one product over } \\
\text { another in the same line of therapy per guidelines }\end{array}$ & 0.0 & 0 & 0.0 & 0 & 1.0 & 5 & 4.8 & 4 \\
\hline Use management tools such as split fills & 1.0 & 5 & 4.8 & 4 & 1.0 & 5 & 4.8 & 4 \\
\hline $\begin{array}{l}\text { Drive use through tiering differentials for like products (same } \\
\text { line of therapy or MOA) }\end{array}$ & 0.0 & 0 & 0.0 & 0 & 0.0 & 0 & 0.0 & 0 \\
\hline $\begin{array}{l}\text { Not providing coverage for off-label use (not FDA approved) } \\
\text { despite NCCN compendia }\end{array}$ & 1.0 & 5 & 4.8 & 4 & 1.0 & 5 & 4.8 & 4 \\
\hline Manage more restrictively than label & 0.0 & 0 & 0.0 & 0 & 0.0 & 0 & 0.0 & 0 \\
\hline \multicolumn{9}{|l|}{ NSCLC: Medicare } \\
\hline Use provider-developed pathways to manage & 1.0 & 5 & 9.0 & 7 & 3.0 & 14 & 15.8 & 13 \\
\hline $\begin{array}{l}\text { Buy-and-bill incentives to influence preference toward generic } \\
\text { agents }\end{array}$ & 0.0 & 0 & 0.0 & 0 & 0.0 & 0 & 0.0 & 0 \\
\hline $\begin{array}{l}\text { Buy-and-bill incentives to influence preference toward branded } \\
\text { agents }\end{array}$ & 0.0 & 0 & 0.0 & 0 & 1.0 & 5 & 2.0 & 2 \\
\hline Use of value frameworks (e.g., ASCO or ICER) & 0.0 & 0 & 0.0 & 0 & 2.0 & 10 & 6.8 & 6 \\
\hline $\begin{array}{l}\text { Enter into risk-sharing agreements with providers using path- } \\
\text { ways (narrower than NCCN guidelines) to manage }\end{array}$ & 0.0 & 0 & 0.0 & 0 & 2.0 & 10 & 6.8 & 6 \\
\hline Clinical pathways for providers, without risk sharing & 0.0 & 0 & 0.0 & 0 & 0.0 & 0 & 0.0 & 0 \\
\hline Excluded an agent from formulary/coverage & 0.0 & 0 & 0.0 & 0 & 1.0 & 5 & 1.3 & 1 \\
\hline $\begin{array}{l}\text { Implement step edits that require use of one product over } \\
\text { another in the same line of therapy per guidelines }\end{array}$ & 0.0 & 0 & 0.0 & 0 & 3.0 & 14 & 8.1 & 7 \\
\hline
\end{tabular}




\section{TABLE 5 Commercial and Medicare Restrictions on NSCLC and CLL Agents Today and Expected} in 3-5 Years (continued)

\begin{tabular}{|c|c|c|c|c|c|c|c|c|}
\hline & \multicolumn{2}{|c|}{\begin{tabular}{|c|} 
Number of Payers \\
Who Restrict Agents \\
Today
\end{tabular}} & \multicolumn{2}{|c|}{$\begin{array}{c}\text { Number of Lives } \\
\text { Today }\end{array}$} & \multicolumn{2}{|c|}{\begin{tabular}{|c|} 
Number of Payers \\
Expected to Restrict \\
Agents in 3-5 Years \\
\end{tabular}} & \multicolumn{2}{|c|}{$\begin{array}{c}\text { Number of Lives in } \\
\text { 3-5 Years }\end{array}$} \\
\hline & $\mathbf{n}$ & $\%$ & $\begin{array}{c}\mathbf{n} \\
\text { (millions) }\end{array}$ & $\%$ & $\mathrm{n}$ & $\%$ & $\begin{array}{c}n \\
\text { (millions) }\end{array}$ & $\%$ \\
\hline \multicolumn{9}{|l|}{ NSCLC: Medicare } \\
\hline Use management tools such as split fills & 0.0 & 0 & 0.0 & 0 & 2.0 & 10 & 6.8 & 6 \\
\hline $\begin{array}{l}\text { Drive use through tiering differentials for like products (same } \\
\text { line of therapy or MOA) }\end{array}$ & 0.0 & 0 & 0.0 & 0 & 1.0 & 5 & 1.3 & 1 \\
\hline $\begin{array}{l}\text { Not providing coverage for off-label use (not FDA approved) } \\
\text { despite NCCN compendia }\end{array}$ & 0.0 & 0 & 0.0 & 0 & 1.0 & 5 & 4.8 & 4 \\
\hline Manage more restrictively than label & 0.0 & 0 & 0.0 & 0 & 1.0 & 5 & 9.0 & 7 \\
\hline \multicolumn{9}{|l|}{ CLL: Medicare } \\
\hline Use provider-developed pathways to manage & 1.0 & 5 & 9.0 & 7 & 0.0 & 0 & 0.0 & 0 \\
\hline $\begin{array}{l}\text { Buy-and-bill incentives to influence preference toward generic } \\
\text { agents }\end{array}$ & 0.0 & 0 & 0.0 & 0 & 0.0 & 0 & 0.0 & 0 \\
\hline $\begin{array}{l}\text { Buy-and-bill incentives to influence preference toward branded } \\
\text { agents }\end{array}$ & 0.0 & 0 & 0.0 & 0 & 0.0 & 0 & 0.0 & 0 \\
\hline Use of value frame works (e.g., ASCO or ICER) & 0.0 & 0 & 0.0 & 0 & 0.0 & 0 & 0.0 & 0 \\
\hline $\begin{array}{l}\text { Enter into risk-sharing agreements with providers using path- } \\
\text { ways (narrower than NCCN guidelines) to manage }\end{array}$ & 0.0 & 0 & 0.0 & 0 & 1.0 & 5 & 9.0 & 7 \\
\hline Clinical pathways for providers, without risk sharing & 0.0 & 0 & 0.0 & 0 & 0.0 & 0 & 0.0 & 0 \\
\hline Excluded an agent from formulary/coverage & 0.0 & 0 & 0.0 & 0 & 0.0 & 0 & 0.0 & 0 \\
\hline $\begin{array}{l}\text { Implement step edits that require use of one product over } \\
\text { another in the same line of therapy per guidelines }\end{array}$ & 0.0 & 0 & 0.0 & 0 & 0.0 & 0 & 0.0 & 0 \\
\hline Use management tools such as split fills & 0.0 & 0 & 0.0 & 0 & 0.0 & 0 & 0.0 & 0 \\
\hline $\begin{array}{l}\text { Drive use through tiering differentials for like products (same } \\
\text { line of therapy or MOA) }\end{array}$ & 0.0 & 0 & 0.0 & 0 & 1.0 & 5 & 9.0 & 7 \\
\hline $\begin{array}{l}\text { Not providing coverage for off-label use (not FDA approved) } \\
\text { despite NCCN compendia }\end{array}$ & 0.0 & 0 & 0.0 & 0 & 0.0 & 0 & 0.0 & 0 \\
\hline Manage more restrictively than label & 0.0 & \begin{tabular}{l|l}
0 \\
\end{tabular} & 0.0 & 0 & 0.0 & \begin{tabular}{l|l}
0 \\
\end{tabular} & 0.0 & 0 \\
\hline \multicolumn{9}{|c|}{$\begin{array}{l}\text { aThere were } 14 \text { pharmacy directors and } 7 \text { medical directors in our sample. Although the sample was not powered to detect statistically significant differences between medi- } \\
\text { cal directors and pharmacy directors, the following differences where } 2 \text { or more payers answered differently were noted: } \\
\text { - In 3-5 years, medical directors indicated they are more likely to drive utilization through tiering differentials for like products (same line of therapy or MOA), with } \\
2 \text { medical directors and no pharmacy directors indicating that they expected to use tiering differentials to drive preference. } \\
\text { - Medical directors were more likely to implement step edits that require use of one product over another in the same line of therapy per guidelines in 3-5 years, with } \\
3 \text { medical directors expecting to implement step edits in the future, and no pharmacy directors expecting to use this tool. } \\
\text { - Medical directors were more likely to use value frameworks, with } 3 \text { medical directors and } 1 \text { pharmacy director expecting to use value frameworks. } \\
\text { ASCO=American Society of Clinical Oncology; CLL=chronic lymphocytic leukemia; FDA=U.S. Food and Drug Administration; ICER=Institute for Clinical and } \\
\text { Economic Review; MOA = mechanism of action; NCCN= National Comprehensive Cancer Network; NSCLC=non-small cell lung cancer. }\end{array}$} \\
\hline
\end{tabular}

increasing ASP for preferred agents. Practice economics of the buy-and-bill market, where practices buy products at ASP and are reimbursed at ASP plus $6 \%$ of the drug cost, create financial incentives for physician-prescribing behavior. Buy-and-bill incentives that tie physician reimbursement to price of product potentially lead to management barriers for the Centers for Medicare \& Medicaid Services (CMS) and commercial payers.

Although secondary research suggests that innovative care environments, such as the Center for Medicare \& Medicaid Innovation's OCM, are becoming more prevalent, few payers in our sample indicated that they were pursuing these types of oncology-specific models today. In addition, it was uncommon for payers in our sample to shift financial risk to providers through payment systems (e.g., bundled payments) or to restructure provider networks based on their ability to control oncology medication cost. This result suggests that payers are reimbursing oncology treatments individually, rather than through capitated payments, which increases uncertainty of cost per patient for a payer and leads to uncertainty in preparing for budget impact.

Most payers are aware of ASCO and Institute for Clinical and Economic Review (ICER) value frameworks, but these frameworks have been only minimally influential on decision making so far. Very few payers develop value frameworks internally, but those who do rely on ICER and NCCN guidelines to provide guidance. 
In 3-5 years, payers reported the intent to use more restrictive traditional management tools, such as step edits independent of NCCN compendia and blocking agents from formulary. Payers also intend to use innovative management tools more. For example, payers indicated that they would be somewhat more likely to use buy-and-bill incentives to manage this category. In addition, payers expressed interest in implementing oncology care models more often than they do today. Payers also expected to restructure provider networks in the future as a management tactic. ASCO and ICER value frameworks are expected to become slightly more influential in 3-5 years. Also, consideration for value-based contracts may increase with the introduction of high-cost, one-time treatments such as CAR-T therapies for acute lymphoblastic leukemia and diffuse large B-cell lymphoma.

When probed specifically regarding NSCLC, only a small portion of the payer sample indicated that they will attempt to manage products more restrictively than label in the future. Consistent with overall findings, few payers will use value frameworks and restructure provider developed pathways to manage NSCLC. For CLL, it will remain highly uncommon for payers to manage products beyond label because CLL has smaller prevalence and is a high unmet need space. It is less likely that value frameworks and restructuring of provider networks will be used to manage this category.

Our research concludes that there will be only minor to moderate changes to management of NSCLC and CLL. Our results suggest that changes are more likely to be seen for larger solid tumors, such as NSCLC, than in smaller, hematological malignancies.

\section{Limitations}

There are some limitations to this study. First, the study was conducted via a mobile application with a nonrandom sample of payers that was not representative of all covered lives, with a sample bias toward commercial payers covering at least 500,000 lives. The payer panel was constructed to include payer organizations with 500,000 reported covered lives or greater, which could bias results by missing smaller plans that may have innovative or unique tools for addressing oncology management. The panel was constructed by recruiting payers in roles willing to participate in market research who were identified through recruiters and online searches. As a result, this cohort inherently represented only payers willing to participate in market research, as well as use an online survey platform. In addition, our payer lives were based on reported lives from payers, who could have biased recollections or differing definitions of their total covered lives populations.

Second, payers were asked to predict management trends over the next 3-5 years individually for decisions ultimately made in the context of a larger organization and team, which may have biased results by placing too much emphasis on an individual in an organization who could misrepresent the totality of the organization. Individual payers may change organizations over time, changing the landscape of decision makers over the next 3-5 years. Also, we did not account for disruptive market events such as pricing or management policy reform.

Finally, concerns of survey fatigue limited the research to 2 case studies to understand the implications for specific disease states, limiting extrapolation to other cases such as orphan oncology indications.

\section{Conclusions}

Despite the rising cost of oncology drugs and the willingness of U.S. payers to control cost, the level of management remains limited in most classes. Even when implementing specific measures such as pathways of care with or without risk, payer ability to limit the use of innovative drugs beyond guidelines is low. This may change in the future, as competition increases (e.g., among PD-1 and PD-L1 inhibitors); more head-to-head data is available; and the cost of some combination therapies becomes higher. Highly competitive areas, especially where multiple high-cost products or a combination of products with mature data compete for the same patient subpopulations, should be monitored, since changes in management may be more likely to occur in these areas.

Many factors contribute to the difficulty of managing products with oncology indications, including a lack of head-tohead trial data, lack of mature evidence, a highly segmented patient population, regulation, complexity and severity of disease, and physician pushback.

Several payers are experimenting with systemic strategies such as shifting the cost to providers and patients (e.g., by moving products to higher copay/coinsurance tiers) and trying new reimbursement mechanisms. However, these management strategies, as well as the use of value frameworks, remain limited pilot programs with uncertain outcomes.

Despite limited use of innovative management tools and strategies in oncology, there are trends worth monitoring. The lack of head-to-head evidence and competition will begin to resolve for indications such as NSCLC. PD-1 inhibitors consistently generate new evidence, and payers have shown interest in adopting aggressive traditional management tools when feasible. If more financial risk is successfully shifted to providers or patients, provider-developed pathways of care and value framework adoption may increase, leading to preference of brands offering a higher perceived value. Hematology oncology remains immune from aggressive management for the time being due to the inability of payers to ration care or access to drugs. Further studies should examine if this finding can be extrapolated to other oncology areas with small or complex populations, such as orphan oncology areas. However, large disease areas with many competing drugs, such as NSCLC or breast cancer, should be monitored closely for increasing payer management. 


\section{Authors}

ANNE RUNYAN, BA; JORDAN BANKS, MPA; and DANIELE SEVERI BRUNI, MS, MKO Global Partners, Powell, Ohio.

AUTHOR CORRESPONDENCE: Daniele Severi Bruni, MS, MKO Global Partners, 110 Riverbend Ave., Ste. 100, Powell, OH 43065. Tel.: 310.220.5511; E-mail: daniele.bruni@mkogp.com.

\section{DISCLOSURES}

No outside funding supported this study. The authors are employed by MKO Global Partners, which is a consulting firm that focuses on payer strategy and market access in the pharmaceutical and biotech markets.

Some initial results from this research were published as part of a comparative poster at ISPOR European Conference; November 4-8, 2017; Glasgow, Scotland, UK.

\section{REFERENCES}

1. Magellan Rx Management. Medical pharmacy trend report. 2017 eighth edition. Available at: https://wwwl.magellanrx.com/media/722153/tr2017_ final_for-website-use.pdf. Accessed November 21, 2018

2. Cancer.Net. Understanding the costs related to cancer care. April 3, 2018 Available at: https://www.cancer.net/navigating-cancer-care/financial-considerations/understanding-costs-related-cancer-care. Accessed November 21, 2018.

3. American Cancer Society. Managing the cost of your cancer treatment. October 23, 2017. Available at: https://www.cancer.org/treatment/findingand-paying-for-treatment/understanding-financial-and-legal-matters/thecost-of-cancer-treatment.html. Accessed November 21, 2018.

4. American Associates, Ben-Gurion University of the Negev. U.S. cancer drug costs increasing despite competition. Science Daily. October 31, 2017. Available at: https://www.sciencedaily.com/releases/2017/10/171031120329. htm. Accessed November 21, 2018

5. IMS Institute for Health Economics. Innovation in cancer care and implications for health systems. Global oncology trend report. May 2014. Available at: http://340breform.org/userfiles/IMSH_Oncology_Trend_ Report.pdf. Accessed November 21, 2018.

6. Bach, PB. Limits on Medicare's ability to control rising spend on cancer drugs. N Engl J Med. 2009; 360(6):626-33. Available at: https://www. nejm.org/doi/10.1056/NEJMhpr0807774?url_ver=Z39.88-2003\&rfr_ id=ori:rid:crossref.org\&rfr_dat $=c r \_p u b \% 3 d w w w . n c b i . n l m . n i h . g o v$. Accessed November 21, 2018.
7. Krasner N, Ragab A, Haren M, Zitter M. Increases of utilization management of oncology medicines by U.S. payers. Am J Pharm Benefits. 2015;8(1):e9-e13. Available at: http://www.ajpb.com/journals/ajpb/2016/ ajpb_januaryfebruary2016/increases-in-utilization-management-of-oncology-medicines-by-us-payers. Accessed November 21, 2018.

8. American Cancer Society. Formularies and drug coverage. January 23, 2014. Available at: https://www.cancer.org/treatment/finding-and-payingfor-treatment/understanding-health-insurance/health-insurance-options/ medicare/medicare-part-d/formularies-and-drug-coverage.html. Accessed November 21, 2018

9. American Cancer Society Cancer Action Network. Out-of-pocket spending limits are crucial for cancer patients \& survivors. January 2, 2018. Available at: https://www.acscan.org/policy-resources/out-pocket-spendinglimits-are-crucial-cancer-patients-survivors. Accessed November 21, 2018.

10. Zafar SY, Peppercorn J, Asabere A, Bastian A. Transparency of industrysponsored oncology patient financial assistance programs using a patientcentered approach. J Oncol Pract. 2017;13(3):e240-e248.

11. Trusheim MR, Berndt ER. The segmentation of therapeutic populations in oncology. Health Management, Policy and Innovation. 2012;1(1):19-34 Available at: http://hmpi.org/wp-content/uploads/2017/02/HMPI-TrusheimBerndt-ONC-segmentation.pdf. Accessed November 21, 2018.

12. Kalemkerian GP, Narula N, Kennedy EB, et al. Molecular Testing Guideline for the Selection of Patients with Lung Cancer for Treatment with Targeted Tyrosine Kinase Inhibitors: American Society of Clinical Oncology endorsement of the College of American Pathologists/International Association for the Study of Lung Cancer/Association for Molecular Pathology Clinical Practice Guideline update. J Clin Oncol. 2018;36(9):911-19.

13. Robinson, James C. Value-based physician payment in oncology: public and private insurer initiatives. Milbank Q. 2017;95(1):184-203. Available at: https://www.ncbi.nlm.nih.gov/pmc/articles/PMC5339382/. Accessed November 21, 2018.

14. Decision Resources Group. Balancing the ever rising cost of oncology drugs: where are we headed? October 14, 2016. Available at: https://decisionresourcesgroup.com/drg-blog/health-reform/balancing-ever-rising-costoncology-drugs-headed/. Accessed November 21, 2018.

15. American Society of Clinical Oncology. ASCO's payment reform model supports higher quality, more affordable cancer care. Available at: https:// practice.asco.org/billing-coding-reporting/macra-quality-payment-program/ alternative-payment-models. Accessed November 21, 2018.

16. Centers for Medicare \& Medicaid Services, Center for Medicare \& Medicaid Innovation. Oncology Care Model. Available at: https://innovation. cms.gov/initiatives/oncology-care/. Accessed November 21, 2018.

17. U.S. Census Bureau. QuickFacts: United States. U.S. trade with Haiti. Available at: https://www.census.gov/quickfacts/fact/table/US/PST0 45216. Accessed November 21, 2018.

18. Henry J. Kaiser Family Foundation. Health insurance coverage of the total population. September 29, 2017. Available at: https://www.kff.org/ other/state-indicator/total-population/. Accessed November 21, 2018. 